\title{
A possible explanation for the refractoriness of uterine prostaglandin production
}

\author{
N. L. Poyser \\ Department of Pharmacology, University of Edinburgh Medical School, I George Square, \\ Edinburgh EH8 9JZ, UK
}

\begin{abstract}
Summary. Arachidonic acid increased the outputs of prostaglandin (PG) F-2 $\alpha$, PGE-2 and 6-keto-PGF-1 $\alpha$ from the Day-7 and Day-15 guinea-pig uterus superfused in vitro. Similar increases in PG output were observed when the arachidonic acid treatment was repeated after an interval of 1,3 or $5 \mathrm{~h}$. Phospholipase (PL) A-2 increased the outputs of PGF-2 $\alpha$, PGE-2 and 6-keto-PGF-1 $\alpha$ from the Day-7 guinea-pig uterus, but repeating the PLA-2 treatment $1 \mathrm{~h}$ later failed to stimulate PG output. The increase in outputs of PGF-2 $\alpha$ and PGE-2 caused by PLA-2 were partly restored after $3 \mathrm{~h}$ and were fully restored after $5 \mathrm{~h}$, whereas the increase in 6-keto-PGF-1 $\alpha$ output produced by PLA- 2 was only partly restored after 3 and $5 \mathrm{~h}$. PLA-2 had little or no effect on PGF- $2 \alpha$ and PGE-2 outputs from the Day-15 guinea-pig uterus initially, and when repeated after 1,3 and $5 \mathrm{~h}$. This was probably due to the output of these two PGs, particularly of PGF-2 $\alpha$, being stimulated in vivo before removal of the uterus. PLA-2 increased 6-keto-PGF-1 $\alpha$ output from the Day-15 uterus initially, but failed to cause a response when administered again $1 \mathrm{~h}$ later. After 3 and $5 \mathrm{~h}$, the increase in 6-ketoPGF-1 $\alpha$ output from the Day-15 uterus caused by PLA- 2 was partly restored. A23187 and PLC increased the outputs of PGF-2 $\alpha$, PGE-2 and 6-keto-PGF-1 $\alpha$ from the Day-7 and Day-15 guinea-pig uterus. These responses to A23187 and PLC were reduced (but not abolished) when the two compounds were administered again $1 \mathrm{~h}$ later. After 3 and $5 \mathrm{~h}$, the increases in output of PGF- $2 \alpha$ and PGE-2 produced by A23187 and PLC had returned to the initial values. The increases in output of 6-keto-PGF-1 $\alpha$ from the Day-7 and Day-15 guinea-pig uterus produced by A23187 and PLC were partly restored after 3 and $5 \mathrm{~h}$, except for the response to PLC on Day 7 which was fully restored after $5 \mathrm{~h}$.

The results show that there is no failure with time in the mechanism which converts arachidonic acid into PGF- $2 \alpha$ in the guinea-pig uterus. The refractoriness of uterine PGF-2 $\alpha$ production following repeated stimulation apparently occurs at the level of arachidonic acid release, particularly as regards the action of PLA-2. There appear to be one or several pools of bound arachidonic acid which are readily releasable but which take $3-5 \mathrm{~h}$ to refill completely. This phenomenon may explain, in part, the pulsatile nature of uterine PGF- $2 \alpha$ release.
\end{abstract}

Keywords: guinea-pig; uterus; phospholipase A-2; phospholipase C; A23187; arachidonic acid; prostaglandins

\section{Introduction}

Studies in several species have shown that prostaglandin (PG) F-2 $\alpha$ release from the uterus is pulsatile (see Poyser, 1981). In sheep, 5 pulses in $24 \mathrm{~h}$ are required in order to cause luteolysis, which produces an inter-pulse interval of $4.8 \mathrm{~h}$ (McCracken et al., 1984). An infusion of oestradiol or oxytocin through the sheep uterus stimulates PGF-2 $\alpha$ synthesis and release (Barcikowski et al., 1974; Roberts et al., 1975). However, this response to the two hormones is not sustained and ffades 
away' even when the stimulus is being continuously applied; this phenomenon effectively produces a pulse of PGF- $2 \alpha$. After oxytocin treatment, the sheep uterus is largely refractory to the PGF- $2 \alpha-$ releasing effect of oxytocin for 4-6 h, but there is no loss of oxytocin receptors (Sheldrick \& Flint, 1986). It appears that the refractoriness of uterine PGF- $2 \alpha$ production is due to an intracellular event, which may explain, in part, the pulsatile nature of uterine PGF- $2 \alpha$ release. This study has investigated which intracellular mechanism involved in the synthesis of PGF- $2 \alpha$ in the uterus exhibits transient failure and could account for the refractoriness of uterine PGF-2 $\alpha$ production, using the superfused guinea-pig uterus.

\title{
Materials and Methods
}

\begin{abstract}
Animals and tests. Virgin guinea-pigs weighing $700-950 \mathrm{~g}$ were examined daily and a vaginal smear was taken when the vagina was perforate. Day 1 of the cycle was taken as the day preceding the post-ovulatory influx of leucocytes when cornification was at the maximum. All guinea-pigs had exhibited at least 2 cycles of normal length before being used on Day 7 or Day 15 of the cycle. The two uterine horns in each of 120 guinea-pigs were removed, weighed and 'opened' by cutting longitudinally. Each uterine horn was suspended in an organ bath and attached to an isotonic lever under a load of $2 \mathrm{~g}$. Both uterine horns from each animal were superfused independently with Krebs' solution ( $5 \mathrm{ml} / \mathrm{min}$; for composition see Mitchell et al., 1977) at $37^{\circ} \mathrm{C}$ pre-gassed with $5 \% \mathrm{CO}_{2}-95 \% \mathrm{O}_{2}$. After an initial settling period of $40 \mathrm{~min}$, samples of superfusate were collected for 10 -min periods continuously or at intervals of $30 \mathrm{~min}$. One uterine horn from each animal was treated for $20 \mathrm{~min}$ with arachidonic acid $(1 \mu \mathrm{g} / \mathrm{ml})$, phospholipase (PL) A-2 $(2 \mathrm{U} / \mathrm{ml})$, the calcium ionophore A23187 $(1 \mu \mathrm{g} / \mathrm{ml})$, or PLC $(2 \mathrm{U} / \mathrm{ml}) 30 \mathrm{~min}$ after starting sample collection, and was treated again for $20 \mathrm{~min}$ with the same compound 1,3 or $5 \mathrm{~h}$ after the end of the first treatment period ( 5 animals/ treatment). The other uterine horn from each animal remained untreated (control).

After collection, the $\mathrm{pH}$ of each sample was lowered to 4.0 with $\mathrm{HCl}$ and the PGs were extracted by shaking twice with $50 \mathrm{ml}$ ethyl acetate. The two ethyl acetate fractions were combined and evaporated to dryness at $50^{\circ} \mathrm{C}$ on a rotary evaporator. The recoveries of PGF- $2 \alpha$ and PGE-2 are $>90 \%$ and the recovery of 6-keto-PGF- $1 \alpha$ is $>80 \%$ by this method (Poyser \& Scott, 1980; Swan \& Poyser, 1983). The results are not corrected for recovery. Each dried extract was redissolved in $10 \mathrm{ml}$ ethyl acetate and stored at $-20^{\circ} \mathrm{C}$. The amounts of PGF-2 $\alpha$, PGE-2 and 6-keto-PGF-1 $\alpha$ present in each sample were measured by radioimmunoassay using antibodies raised in this laboratory and whose cross-reactivities have been reported elsewhere (Poyser, 1987). The inter- and intra-assays coefficients of variation were $<12 \%$. The detection limit was $20-30$ pg PG per assay tube.
\end{abstract}

Sources of material. Arachidonic acid, PLA-2 (EC 3.1.1.4, from Naja naja venom), A23187 and PLC (EC 3.1.4.3, from Clostridium perfringens) were purchased from Sigma Chemical Co., Poole, Dorset, UK.

Statistical tests. Changes in the output of PGs with time were analysed by Duncan's multiple range test or, if the variances of the groups were significantly different by the variance ratio $F$ test, by the paired $t$ test.

\section{Results}

All results in Figs 1-8 are expressed as mean ( \pm s.e.m., $n=5$ ), although in some of the figures the standard errors are smaller than the symbols used and are therefore not shown. The basal amounts of PGF-2 $\alpha$, PGE-2 and 6-keto-PGF-1 $\alpha$ were generally 20 -fold, 2-fold and 1-5-fold higher, respectively, from the Day-15 uterus than from the Day-7 uterus. PGF- $2 \alpha$ output from the Day-15 uterus significantly $(P<0.05)$ decreased with time (Figs 2, 4, 6 and 8$)$.

Arachidonic acid significantly $(P<0.05)$ increased the outputs of PGF-2 $\alpha$, PGE-2 and 6-ketoPGF-1 $\alpha$ from the Day-7 and Day-15 guinea-pig uterus during the first period of stimulation. Arachidonic acid also significantly $(P<0.05)$ increased the outputs of these 3 PGs when applied 1 , 3 or $5 \mathrm{~h}$ later, and there was no reduction in the responses produced (Figs 1 and 2 ).

PLA-2 significantly $(P<0.05)$ increased the outputs of PGF-2 $\alpha$, PGE-2 and 6-keto-PGF-1 $\alpha$ from the Day-7 guinea-pig uterus during the first period of stimulation. However, there were no significant increases in the outputs of PGF-2 $\alpha$, PGE-2 and 6-keto-PGF-1 $\alpha$ from the Day-7 uterus when the PLA-2 was applied $1 \mathrm{~h}$ later (Fig. 3). When applied $3 \mathrm{~h}$ later, PLA-2 caused a small, significant $(P<0.05)$ increase in the outputs of PGF-2 $\alpha$ and 6-keto-PGF-1 $\alpha$ from the Day-7 uterus (Fig. 3). After an interval of 5 h, PLA-2 significantly $(P<0.05)$ increased the outputs of PGF-2 $\alpha$, 
(i) PGF-2 $\alpha$

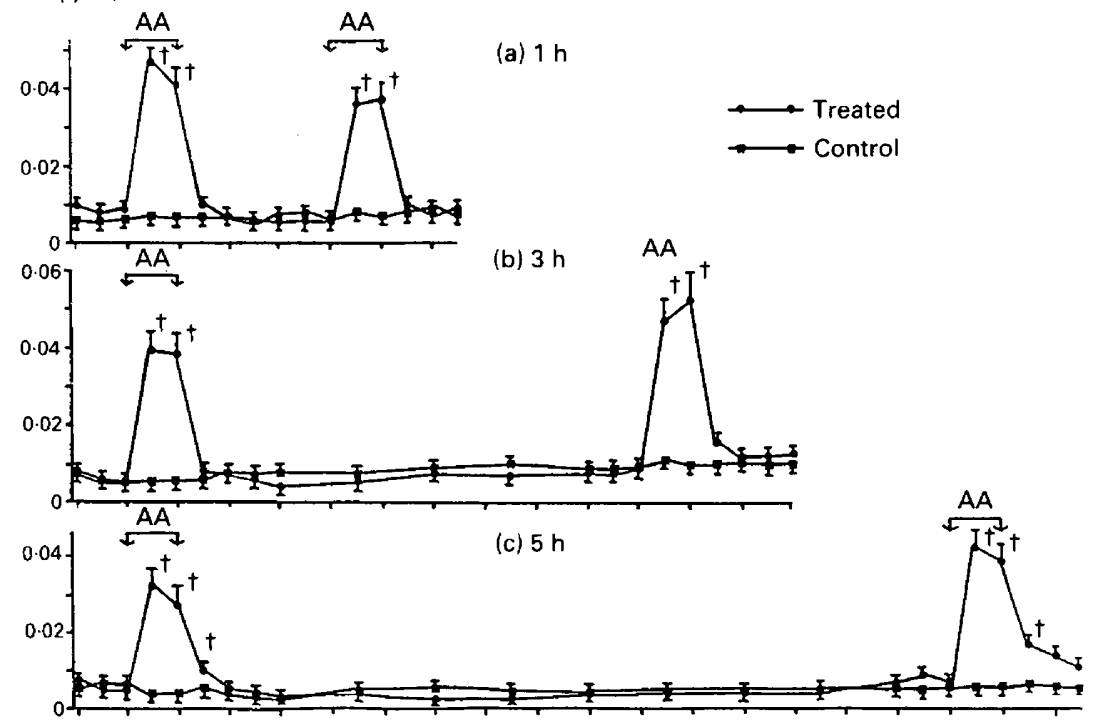

(ii) PGE-2
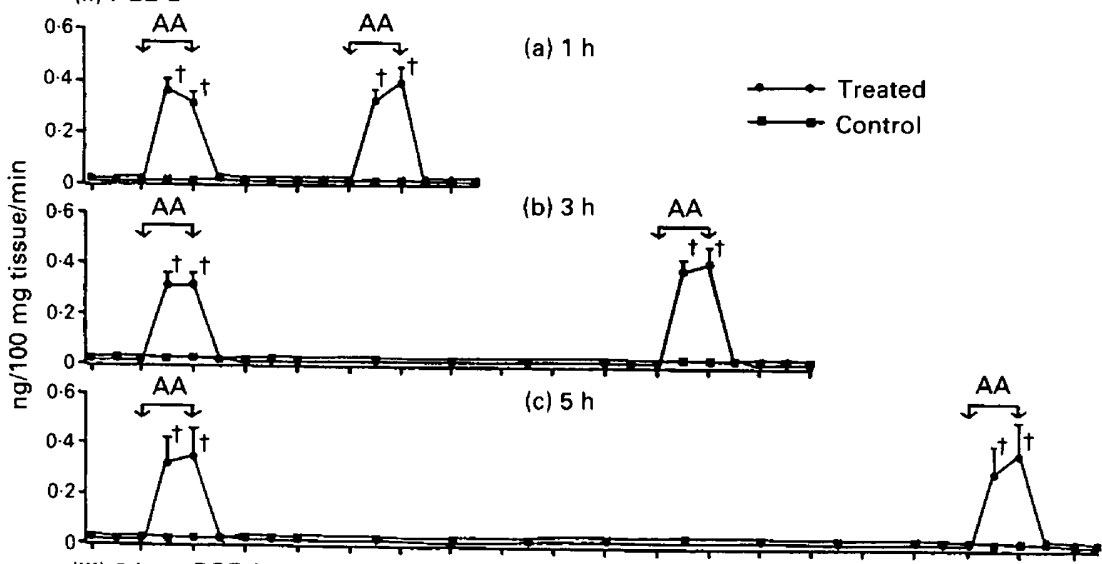

(iii) 6-keto-PGF-1 $\alpha$
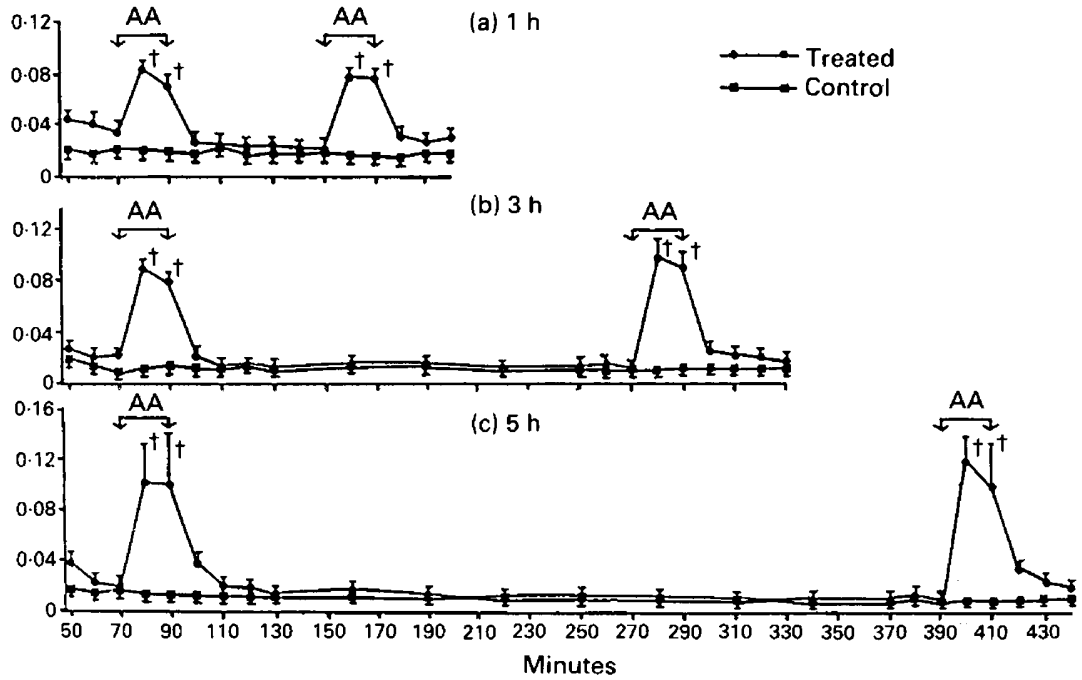

Fig. 1. Effects of arachidonic acid (AA) on mean ( \pm s.e.m., $n=5$ ) outputs of prostaglandin (PG) F-2 $\alpha$, PGE-2 and 6-keto-PGF-1 $\alpha$ from the Day-7 guinea-pig uterus following repeated treatment at intervals of 1,3 and $5 \mathrm{~h}$. $\uparrow$ Significantly $(P<0.05)$ higher than immediately before AA treatment. 

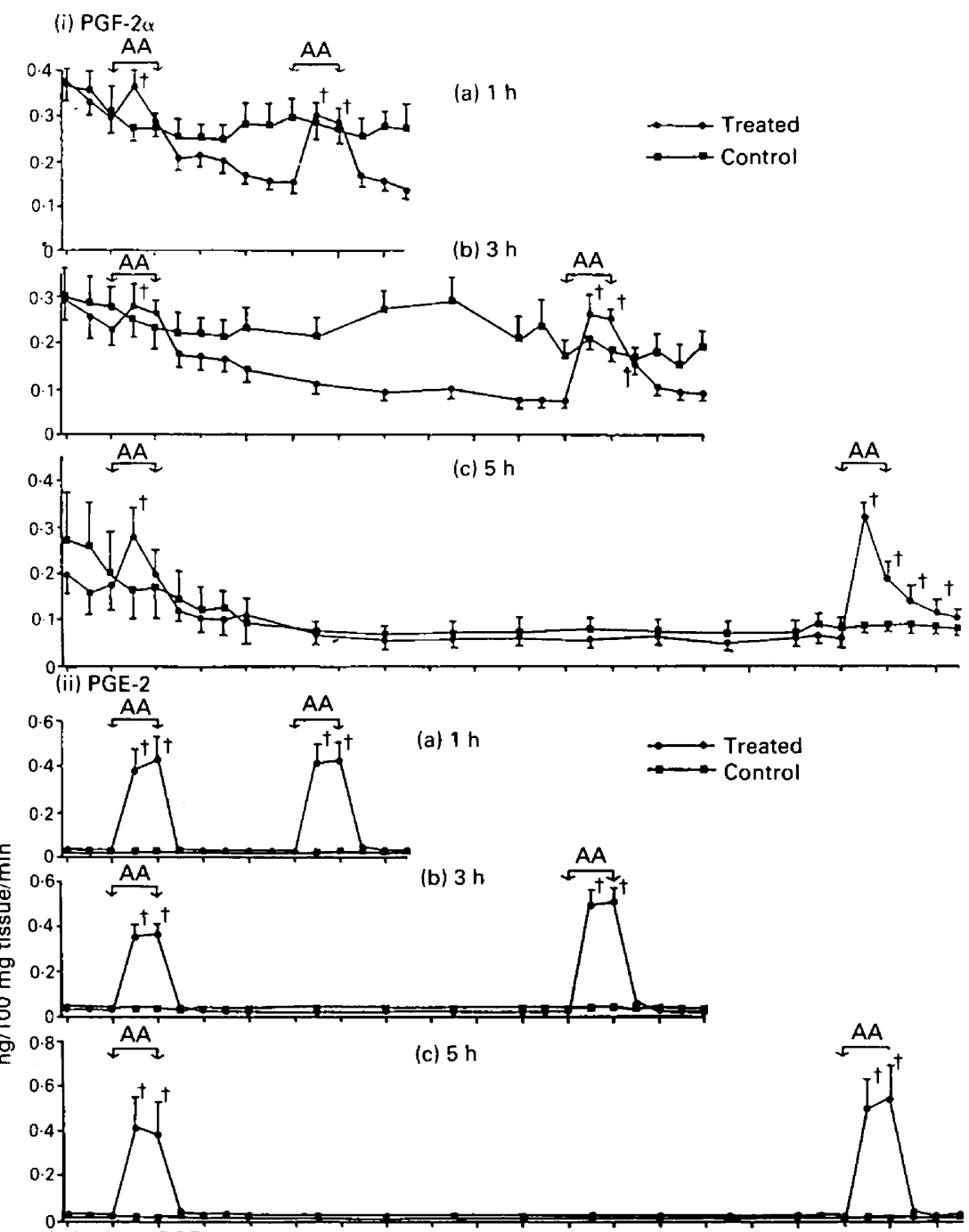

(iii) 6-keto-PGF-1 $\alpha$
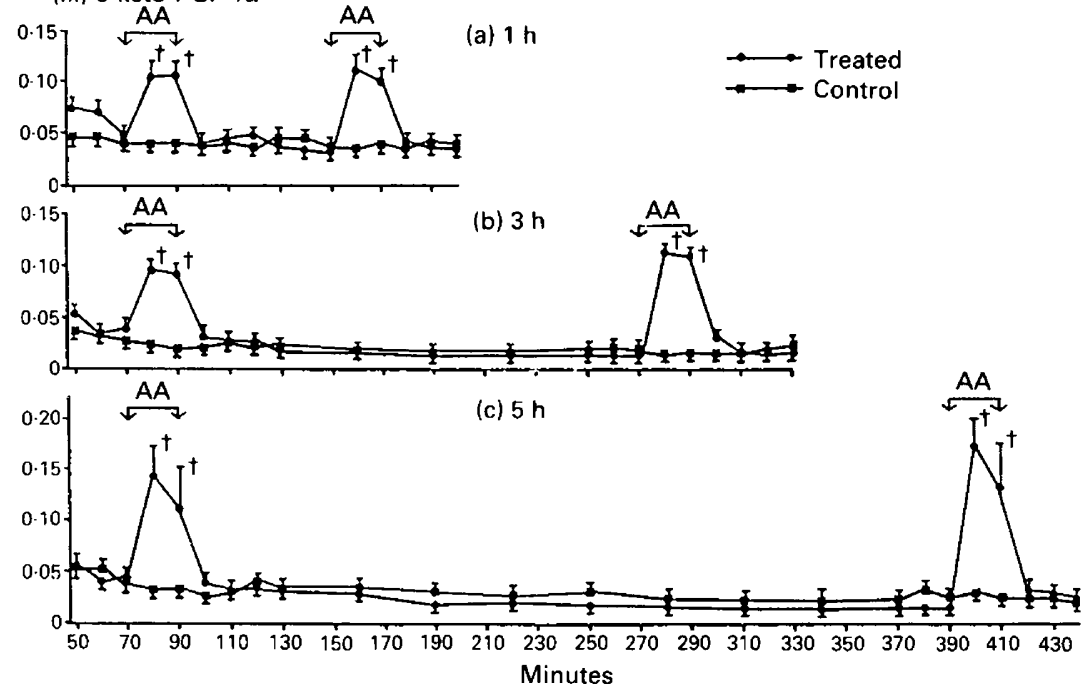

Fig. 2. Effects of arachidonic acid (AA) on mean ( \pm s.e.m., $n=5$ ) outputs of prostaglandin (PG) F-2 $\alpha$, PGE-2 and 6-keto-PGF-1 $\alpha$ from the Day-15 guinea-pig uterus following repeated treatment at intervals of 1,3 and $5 \mathrm{~h}$. † Significantly $(P<<0 \cdot 05)$ higher than immediatelyo before AA treatment. 
(i) PGF- $2 \alpha$

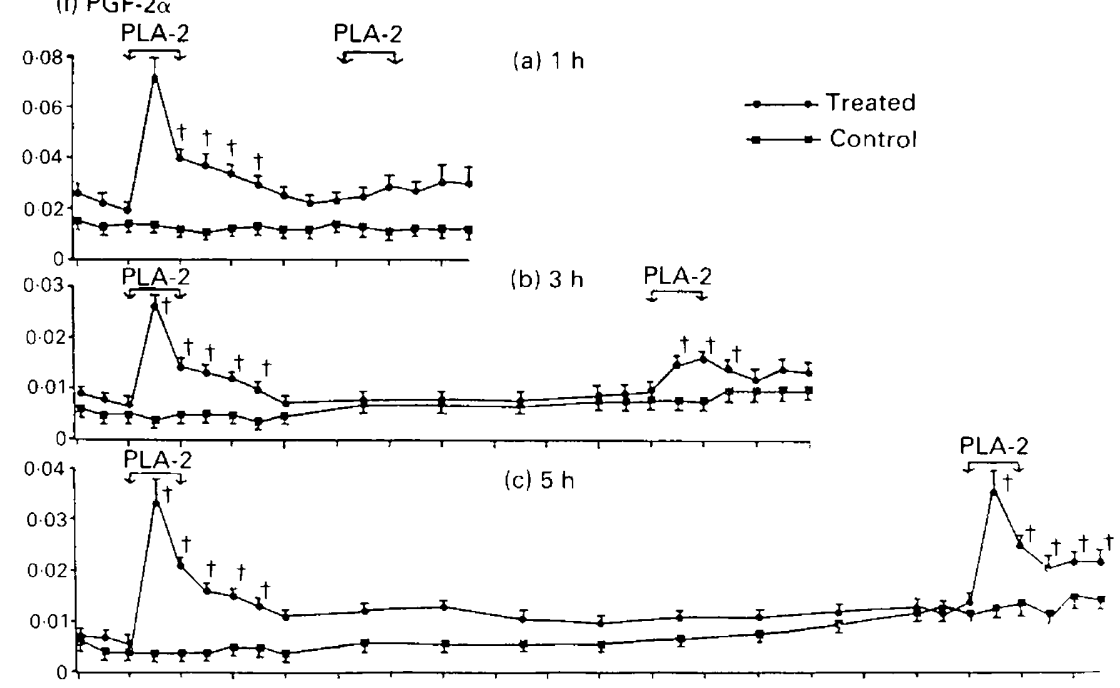

(ii) PGE-2

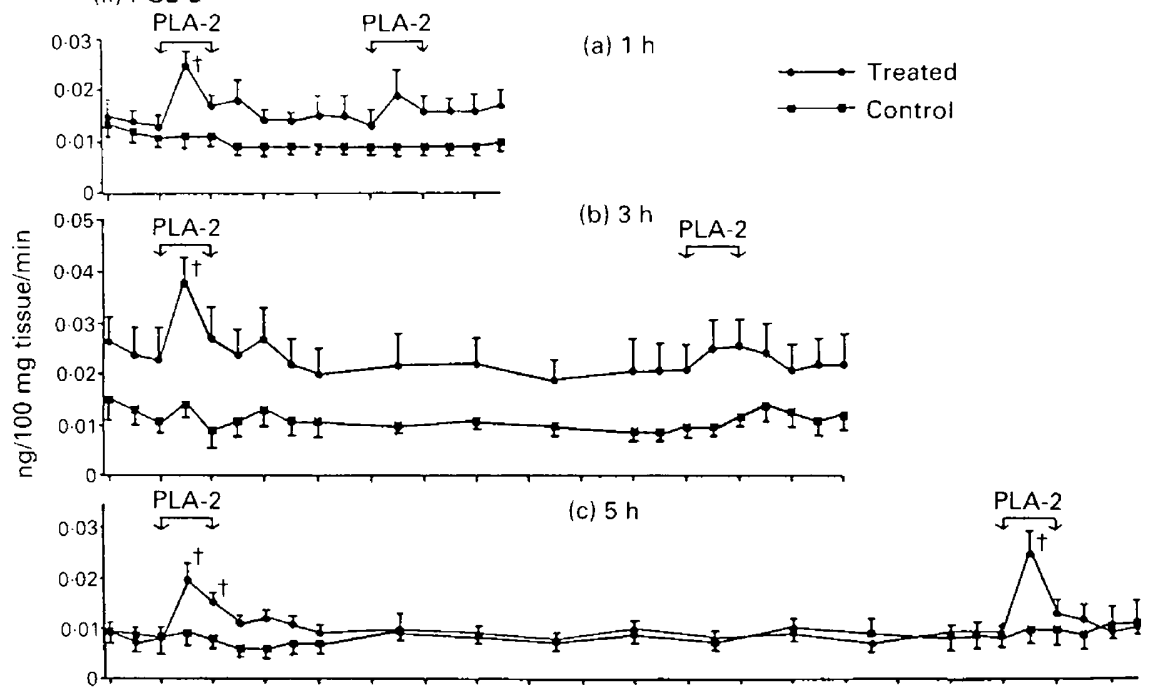

(iii) 6-keto-PGF-1 1 (
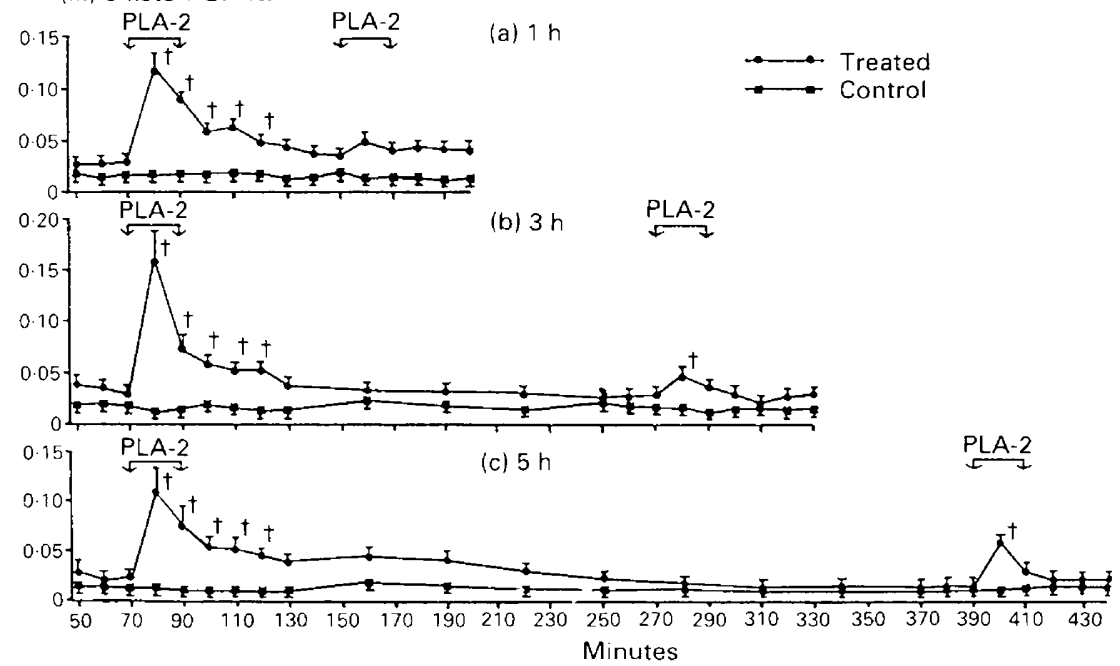

Fig. 3. Effects of phospholipase A-2 (PLA-2) on mean ( \pm s.e.m., $n=5$ ) outputs of prostaglandin (PG) F-2 $\alpha$, PGE-2 and 6-keto-PGF-1 $\alpha$ from the Day-7 guinea-pig uterus following

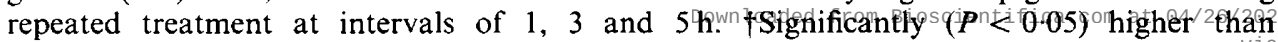
immediately before PLA-2 treatment. 
(i) PGF- $2 \alpha$

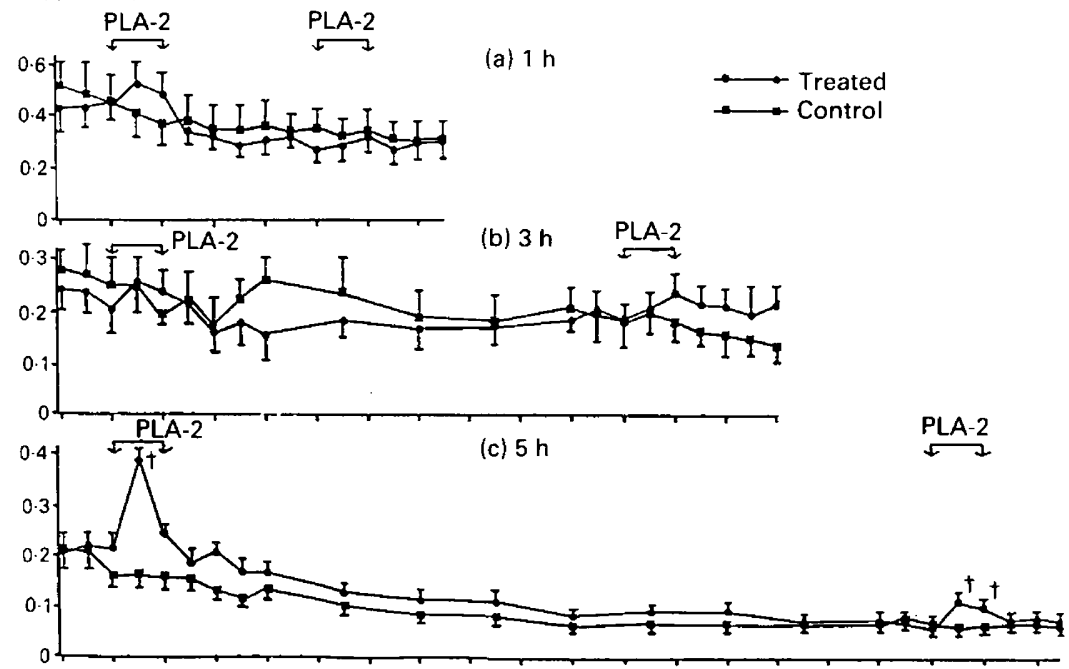

(ii) PGE-2

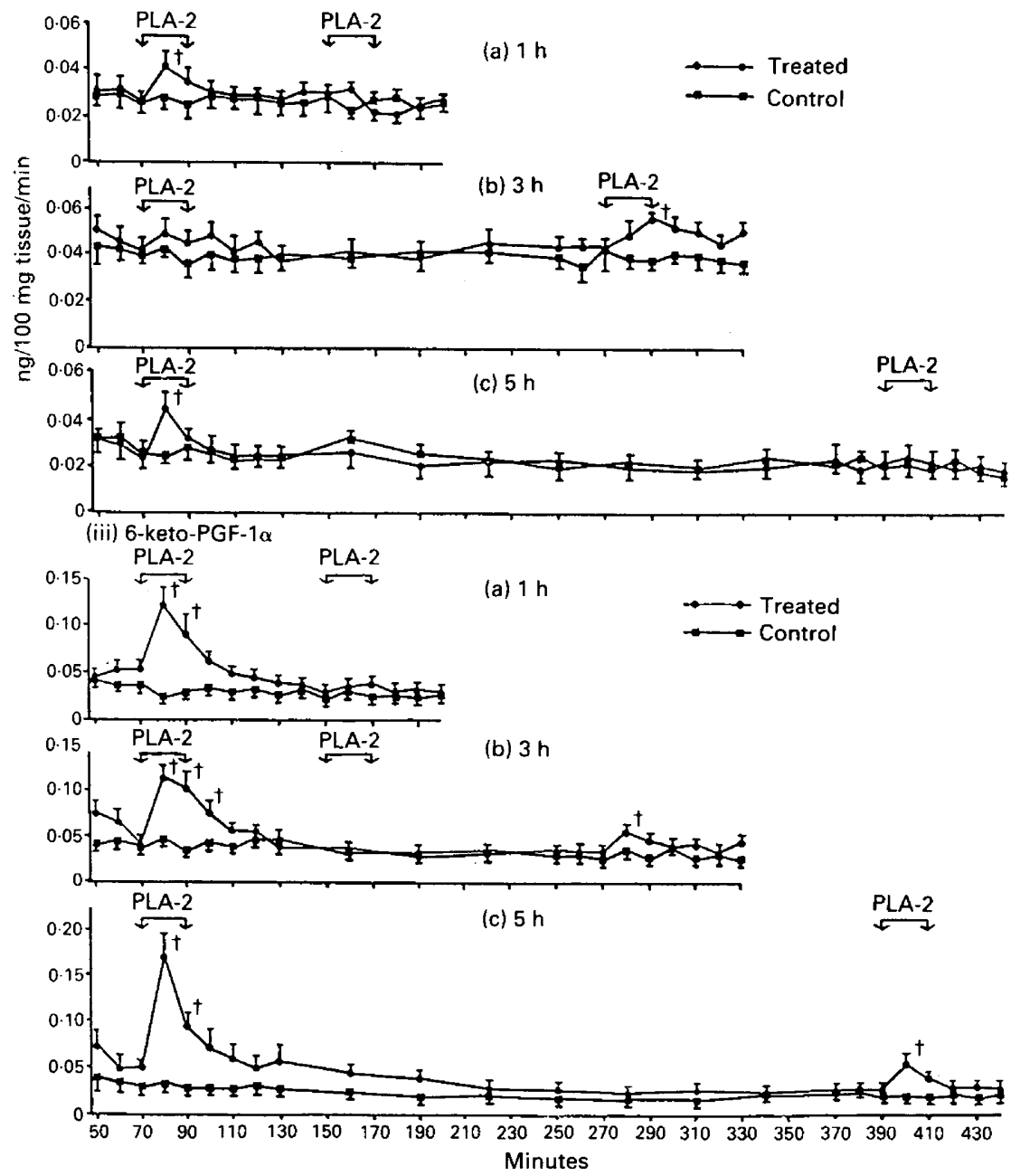

Fig. 4. Effects of phospholipase A-2 (PLA-2) on mean ( \pm s.e.m., $n=5$ ) outputs of prostaglandin (PG) F-2 $\alpha$, PGE-2 and 6-keto-PGF-1 $\alpha$ from the Day-15 guinea-pig uterus following repeated treatment at intervals of 1,3 and $5 \mathrm{~h}$. †Significantly $(P<0.05)$ higher than immediately before PLA-2 treatment. 


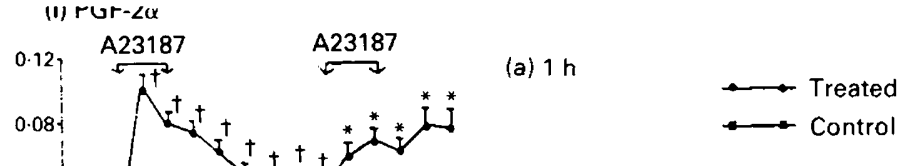


PGE-2 and 6-keto-PGF-1 $\alpha$ fom the Day-7 uterus and the increased outputs of PGF-2 $\alpha$ and PGE-2 were of similar magnitude to the initial increased outputs in response to PLA-2. However, the magnitude of the output of 6-keto-PGF-1 $\alpha$ after $5 \mathrm{~h}$ was significantly $(P<0.05)$ lower than the magnitude of the initial increased output produced by PLA-2 (Fig. 3).

PLA-2 significantly $(P<0.05)$ increased the outputs of 6-keto-PGF-1 $\alpha$ (all 3 instances), PGE-2 ( 2 instances) and PGF-2 $\alpha$ ( 1 instance) from the Day-15 guinea-pig uterus during the first period of stimulation (Fig. 4). PLA-2 had no stimulatory effect on the outputs of the 3 PGs when applied $1 \mathrm{~h}$ later. After an interval of $3 \mathrm{~h}$, PLA-2 caused a small, significant $(P<0.05)$ increase in the outputs of PGE-2 and 6-keto-PGF-1 $\alpha$ from the Day-15 uterus (Fig. 4). When applied $5 \mathrm{~h}$ later, PLA-2 produced a small, significant $(P<0.05)$ increase in the outputs of PGF-2 $\alpha$ and 6-keto-PGF-1 $\alpha$ (Fig. 4).

A23187 significantly $(P<0.05)$ increased the outputs of PGF-2 $\alpha$, PGE-2 and 6-keto-PGF-1 $\alpha$ from the Day-7 and Day-15 guinea-pig uterus during the first period of stimulation (Figs 5 and 6). Following treatment, the basal output of PGs from the Day-7 uterus remained elevated for a prolonged period (Fig. 5). When applied after an interval of $1 \mathrm{~h}, \mathrm{~A} 23187$ caused a small, significant $(P<0.05)$ increase in the outputs of PGF-2 $\alpha$ and 6-keto-PGF-1 $\alpha$ from the Day-7 and Day-15 uterus, and of PGE-2 from the Day-15 uterus (Figs 5 and 6). After intervals of 3 and $5 \mathrm{~h}, \mathrm{~A} 23187$ significantly $(P<0.05)$ increased the outputs of PGF- $2 \alpha$ and PGE-2 from the Day-7 and Day-15 uterus to similar magnitudes when compared with the first period of stimulation. Although A23187 significantly $(P<0.05)$ increased the amounts of 6-keto-PGF-1 $\alpha$ from the Day-7 and Day-15 uterus after intervals of 3 and $5 \mathrm{~h}$, the magnitude of the responses was significantly $(P<0.05)$ lower than the magnitude of the initial responses (Figs 5 and 6). In addition, following the termination of the second treatment with A23187 after 1, 3 and $5 \mathrm{~h}$, there was a secondary increase in output of all 3 PGs on both days (Figs 5 and 6).

PLC significantly $(P<0.05)$ increased the outputs of PGF-2 $\alpha$, PGE-2 and 6-keto-PGF-1 $\alpha$ from the Day-7 and Day-15 guinea-pig uterus during the first period of stimulation (Figs 7 and 8 ). When applied after an interval of $1 \mathrm{~h}$, PLC significantly $(P<0.05)$ increased the outputs of all 3 PGs from the Day-7 and Day-15 uterus. The magnitude of the increase in PGF-2 $\alpha$ output was significantly $(P<0.05)$ lower than the magnitude of the initial output from the uterus on Day-7, but not on Day-15 where there was no significant difference. The increases in the outputs of PGE-2 and 6-keto-PGF-1 $\alpha$ after $1 \mathrm{~h}$ were significantly $(P<0.05)$ lower than the initial increases produced by PLC on the Day-7 and Day-15 uterus (Figs 7 and 8 ). The basal outputs of PGF-2 $\alpha$, PGE-2 and 6-keto-PGF-1 $\alpha$ significantly $(P<0.05)$ increased approximately 100 to $130 \mathrm{~min}$ following the end of the first period of PLC treatment and remained elevated. Nevertheless, PLC significantly $(P<0.05)$ increased the outputs of PGF-2 $\alpha$, PGE-2 and 6-keto-PGF-1 $\alpha$ from the Day-7 and Day-15 uterus after treatment intervals of 3 and $5 \mathrm{~h}$. The magnitude of the increases in PGF-2 $\alpha$ and PGE-2 outputs were similar to or significantly $(P<0.05)$ higher than the initial responses, whereas the magnitude of the increases in 6-keto-PGF-1 $\alpha$ were significantly $(P<0.05)$ lower than the initial responses with the exception of 6-keto-PGF-l $\alpha$ output after $5 \mathrm{~h}$ on Day 7 (Figs 7 and 8).

\section{Discussion}

There was no failure with time over a 5-h period in the biochemical processes which convert arachidonic acid into prostaglandins in the guinea-pig uterus. This indicates that the refractoriness

Fig. 6. Effects of A23187 on mean ( \pm s.e.m., $n=5$ ) outputs of prostaglandin (PG) F-2 $\alpha$, PGE-2 and 6-keto-PGF-1 $\alpha$ from the Day-15 guinea-pig uterus following repeated treatment at intervals of 1,3 and $5 \mathrm{~h}$. †Significantly $(P<0.05)$ higher than the values immediately before A23187 treatment. 
(i) PGF-2 $\alpha$

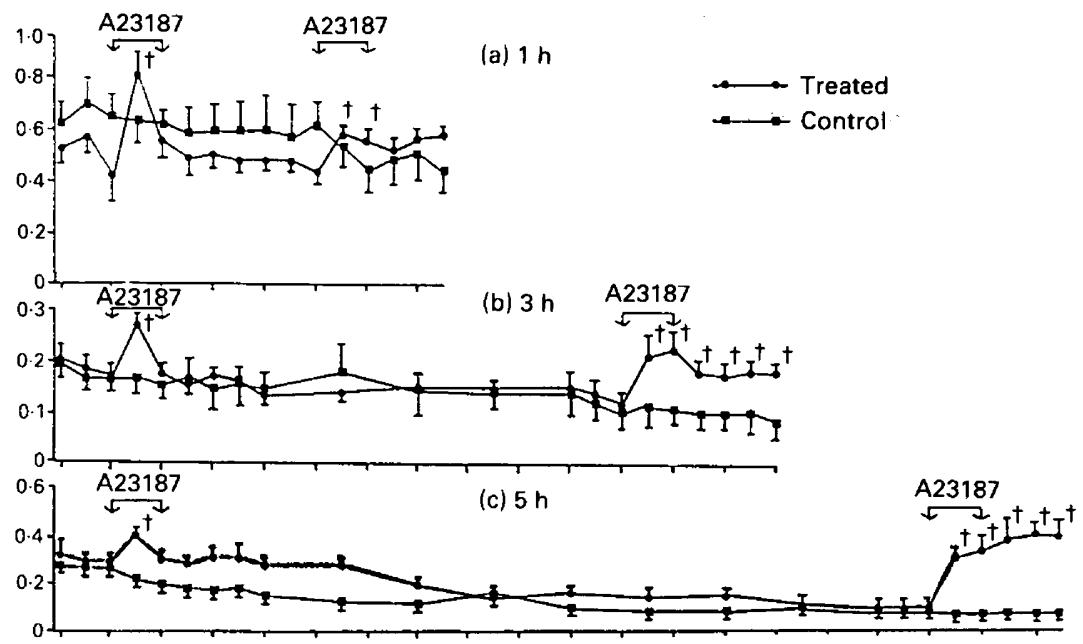

(ii) PGE-2

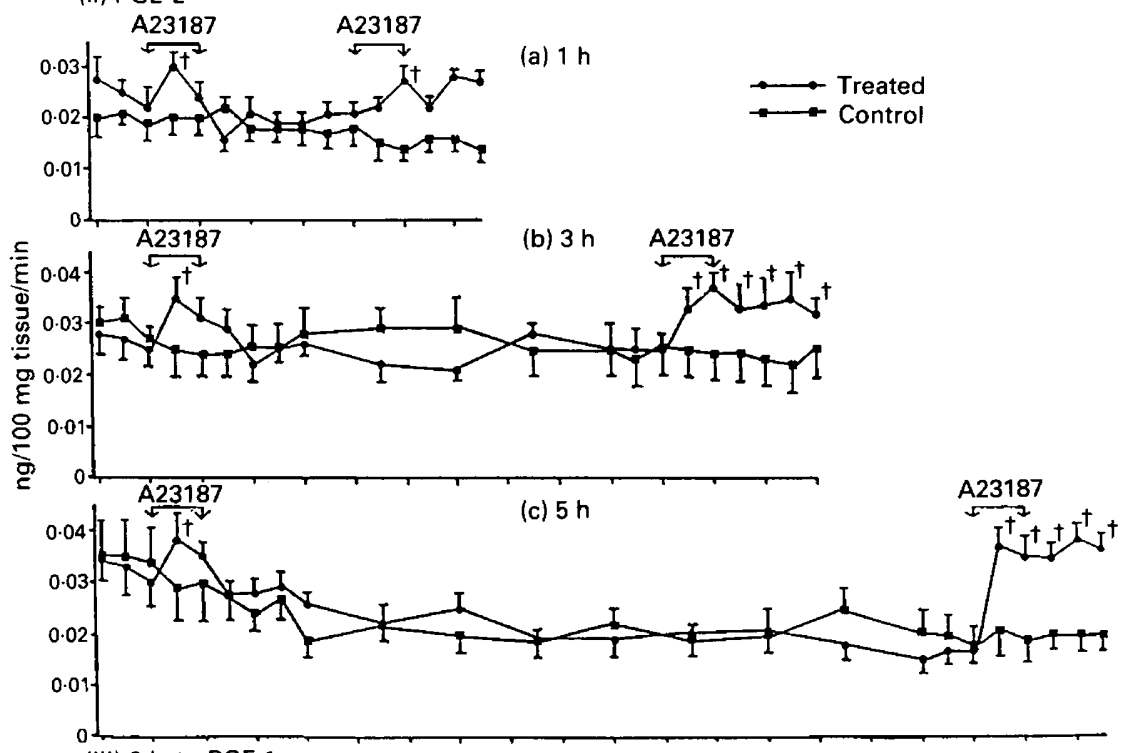

(iii) 6-keto-PGF-1 $\alpha$
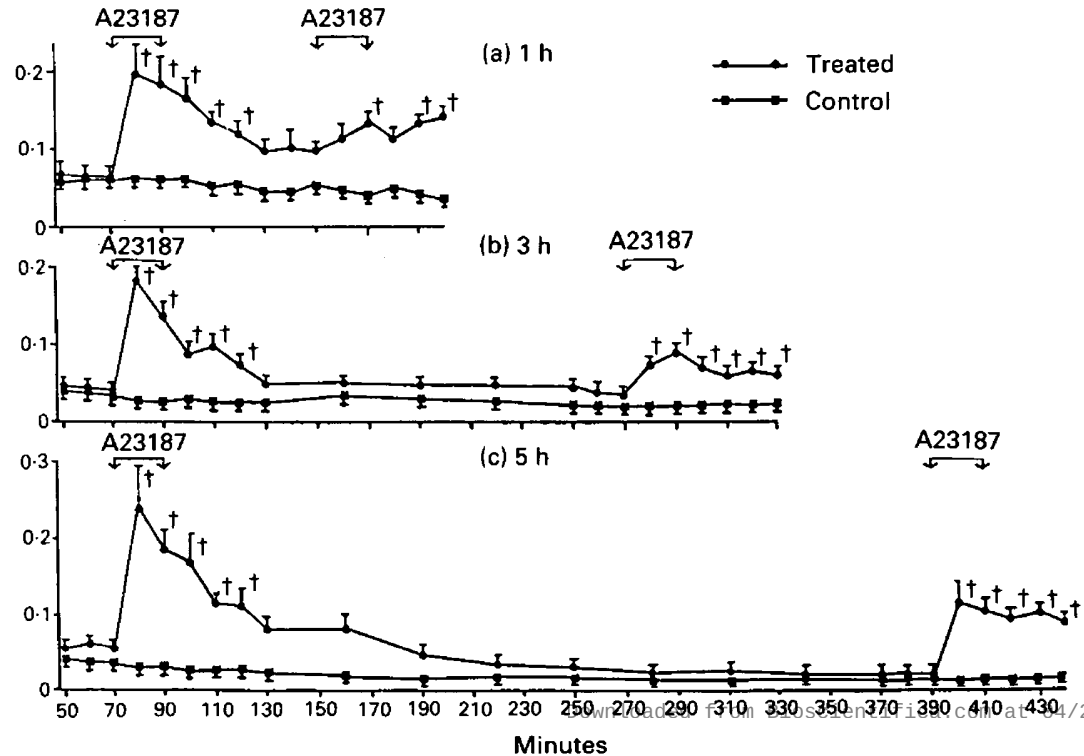
(i) PGF-2o

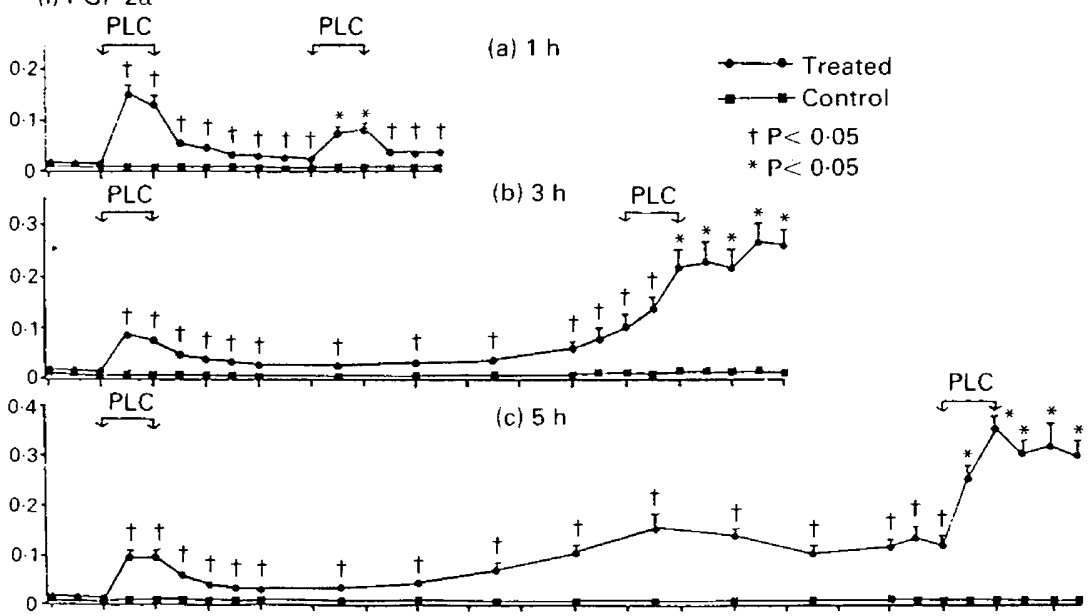

(ii) PGE-2

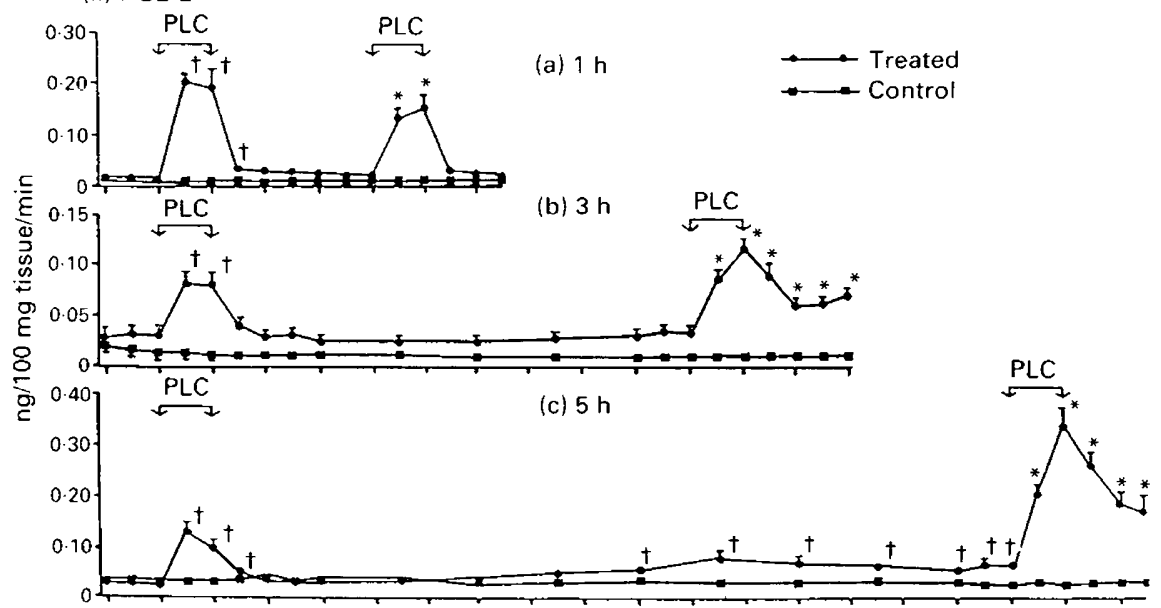

(iii) 6-keto-PGF-1 $\alpha$

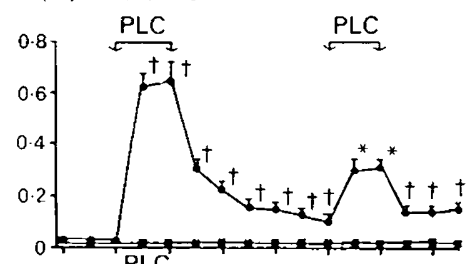

(a) $\uparrow \mathrm{h}$
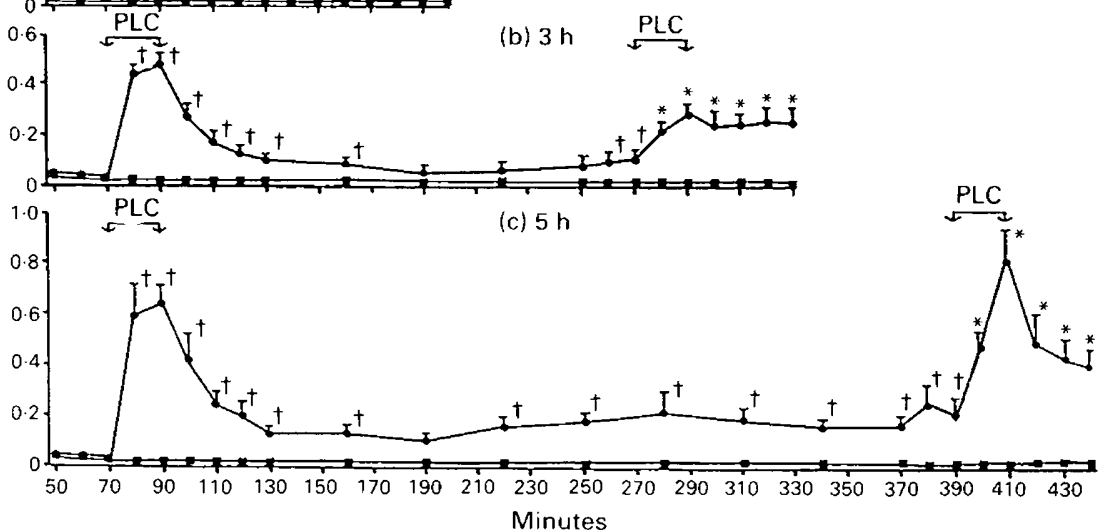

Fig. 7. Effects of phospholipase C (PLC) on mean $( \pm$ s.e.m., $n=5$ ) outputs of prostaglandin (PG) F-2 $\alpha$, PGE-2 and 6-keto-PGF-l $\alpha$ from the Day-7 guinea-pig uterus following repeated treatment at intervals of 1,3 and $5 \mathrm{~h}$. † Significantly $(P<0.05)$ higher than the values immediately before the first period of PLC treatment. ${ }^{2}$ Significantly $(P<0.05)$ higher than the yalues immediately before the second period of PLC treatment. 
(i) PGF- $2 \alpha$

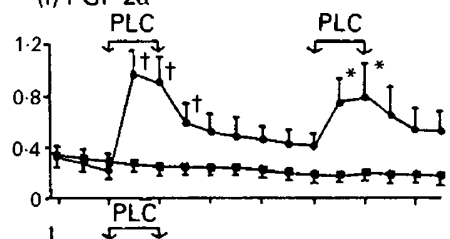

(a) $1 \mathrm{~h}$

$\longrightarrow$ Treated

$\rightarrow$ Control

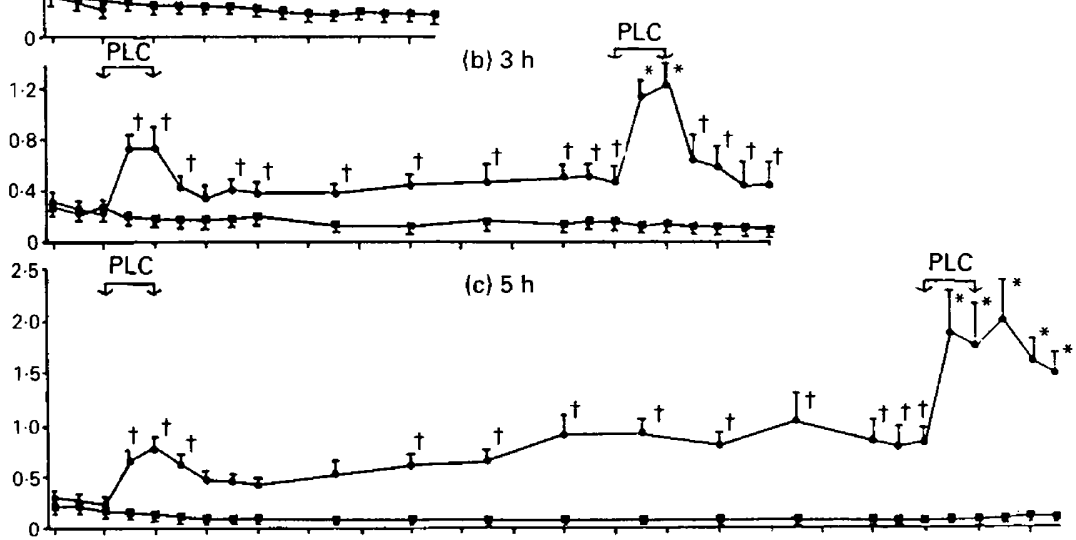

(ii) PGF-2

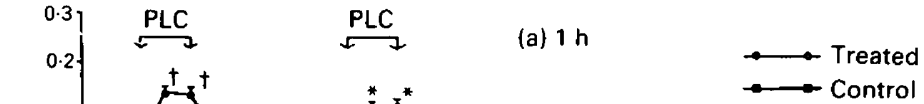

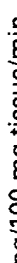

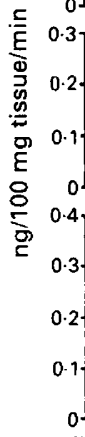

(iii) 6-keto-PGF-1 $\alpha$

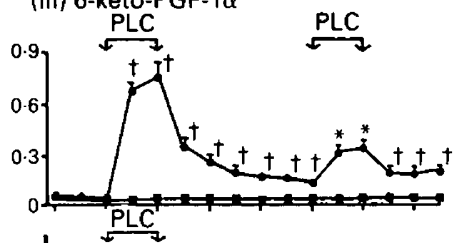

(a) $1 \mathrm{~h}$

$\longrightarrow$ Treated

$\rightarrow$ Control

(b) $3 \mathrm{~h} \quad \stackrel{\mathrm{PLC}}{\longleftarrow}$
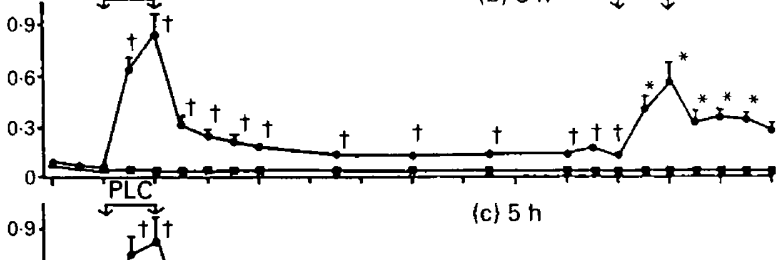

(c) $5 \mathrm{~h}$

PLO

0.6

0.3

(t)

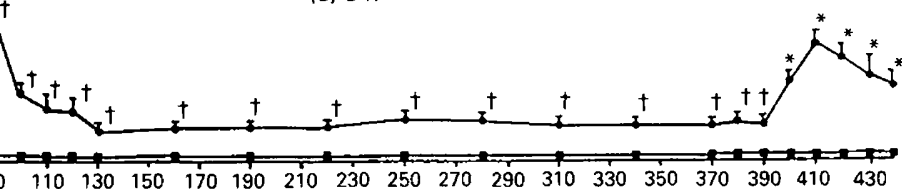

Minutes

Fig. 8. Effects of phospholipase C (PLC) on mean ( \pm s.e.m., $n=5$ ) outputs of prostaglandin (PG) F-2 $\alpha$, PGE-2 and 6-keto-PGF-1 $\alpha$ from the Day-15 guinea-pig uterus following repeated treatment at intervals of 1,3 and $5 \mathrm{~h}$. $†$ Significantly $(P<0.05)$ higher than the values immediately before the first period of PLC treatment. *Significantly $\left(P^{m}<0^{*}, 05\right)$ higher than the values immediately before the second period of PLC treatment.

via free access 
of uterine PGF-2 $\alpha$ production following repeated stimulations is not due to lack or inactivity of PGH synthase and/or PGF reductase. In contrast, following the initial stimulation of the Day-7 guinea-pig uterus by PLA-2, it was not until $5 \mathrm{~h}$ later that PLA-2 was able to stimulate the outputs of PGF-2 $\alpha$ and PGE- 2 to the same magnitude as produced by the initial stimulation, and even then the output of 6-keto-PGF-1 $\alpha$ was still suppressed. These results suggest that there is a pool of bound arachidonic acid which is readily releasable by PLA-2 but takes $3-5 \mathrm{~h}$ to refill completely. The small or lack of stimulatory effect of PLA-2 on PGF-2 $\alpha$ and PGE-2 production by the Day-15 uterus is probably due to endogenous PLA-2 having been stimulated in vivo before removal of the uterus, especially as phosphatidylcholine (PC) and phosphatidylethanolamine (PE) appear to be the source of arachidonic acid for PGF- $2 \alpha$ synthesis in the guinea-pig uterus (Leaver \& Poyser, 1981; Ning et al., 1983; Ning \& Poyser, 1984). Consequently, exogenous PLA-2 could produce little further effect. The fact that exogenous PLA-2 was able to stimulate markedly 6-keto-PGF-1 $\alpha$ synthesis by the Day-15 guinea-pig uterus during the first period of stimulation suggests that a different pool of arachidonic acid and a PLA-2 enzyme located in a different site are used for the production of 6-keto-PGF-1 $\alpha$ than those which are used for the production of PGF-2 $\alpha$ and PGE-2. This pool of arachidonic acid for 6-keto-PGF-1 $\alpha$ production takes longer than $5 \mathrm{~h}$ to refill completely. This difference agrees with previous findings which indicated that the syntheses of PGF-2 $\alpha$ and 6-keto-PGF-1 $\alpha$ in the guinea-pig endometrium are controlled by different intracellular processes (Riley \& Poyser, 1987, 1990).

The stimulation of uterine PG output by A23187, which is dependent upon the presence of extracellular $\mathrm{Ca}^{2+}$ (Poyser, 1984), showed partial refractoriness when A23187 was administered again $1 \mathrm{~h}$ later, but the stimulation of PGF-2 $\alpha$ and PGE-2 (but not 6-keto-PGF-1 $\alpha$ ) outputs had fully recovered by $3 \mathrm{~h}$. Although A23187 and PLA-2 produced similar profiles of PG output, i.e. a large stimulation of PGF-2 $\alpha$ and 6-keto-PGF-1 $\alpha$ outputs and a small stimulation of PGE-2 output (Poyser, 1987), it would appear that A23187 is not acting solely by causing the stimulation of endogenous PLA-2, especially as A23187 in contrast to exogenous PLA-2 has a marked stimulatory effect on the Day-15 uterus.

PLC, like A23187, exhibited partial refractoriness when administered $1 \mathrm{~h}$ after the initial treatment on Day 7 (but not on Day 15), and the increases in output of PGF-2 $\alpha$ and PGE-2 in response to PLC were restored to normal after treatment intervals of 3 and $5 \mathrm{~h}$. The increases in output of 6-keto-PGF-1 $\alpha$ produced by PLC were not fully restored after 3 and $5 \mathrm{~h}$ on Day 7 . The shorter periods of refractoriness produced by A23187 and PLC may indicate that A23187 is also stimulating endogenous PLC. However, exogenous PLC produces a large stimulation of PGE-2 synthesis whereas A23187 has only a weak stimulatory effect on PGE-2 production. However, the exogenous PLC used acts on PC as well as phosphatidylinositol (PI), and it is not known whether the guinea-pig uterus contains a PLC enzyme which can act on PC. The guinea-pig uterus is a rich source of a PLC enzyme specific for PI (Bennett \& Crooke, 1987), but it is not known what effect this enzyme has on PGE-2 synthesis.

The partial and short refractory period to PLC of the Day-7 guinea-pig uterus and lack of refractory period to PLC of the Day-15 guinea-pig uterus as regards PGF-2 $\alpha$ synthesis essentially agrees with the findings in the sheep uterus of Vallet \& Bazer (1989), who concluded that their results concerning inositol phosphate formation (by the action of PLC) following oxytocin treatment "do not support the concept that the refractory period caused by oxytocin administration results from a decrease in phosphatidylinositol turnover." Although it is clear that the sheep uterus contains the necessary enzymes (i.e. PLC, diglyceride lipase and monoglyceride lipase) to release arachidonic acid from PI (Flint et al., 1986), the actual phospholipid source of arachidonic acid for PGF-2 $\alpha$ synthesis in the sheep uterus has still to be established. Consequently, it is not known whether the action of PLA-2 on PC and/or PE, or the action of PLC on PI is the more important pathway for providing arachidonic acid for PGF-2 $\alpha$ synthesis in the sheep uterus. It is possible that intracellular $\mathrm{Ca}^{2+}$, released by inositol triphosphate which is formed by the action of PLC on phosphatidylinositol-4,5-biphosphate, activates PLA-2 to release arachidonic acid for PGF-2 $\alpha$ 
synthesis in the sheep uterus, thus linking the PLC and PLA-2 pathways. However, neomycin (an inhibitor of PLC) prevents inositol triphosphate formation but not thromboxane formation in response to fluoroaluminate in human platelets (Fuse \& Tai, 1987), indicating that activation of PLC and PLA-2 are two separate processes which are not interdependent and that, although PLC is activated, arachidonic acid release is due to the direct stimulation of PLA-2 in this cell type. Similar experiments need to be done with the sheep uterus to establish the source of arachidonic acid for PGF-2 $\alpha$ synthesis. In the guinea-pig uterus, there is no increase in PI turnover at the time of increased uterine PGF-2 $\alpha$ synthesis (Ning \& Poyser, 1984), particularly as oxytocin does not stimulate uterine PG synthesis at the end of the cycle in this species (Poyser \& Brydon, 1983; Riley $\&$ Poyser, 1987). All the evidence in the guinea-pig indicates that PLA-2 acts on PC and PE, but not PI, to release arachidonic acid for PGF-2 $\alpha$ synthesis (Leaver \& Poyser, 1981; Ning et al., 1983; Downing \& Poyser, 1983; Ning \& Poyser, 1984).

In conclusion, the refractoriness of uterine PGF-2 $\alpha$ production in the guinea-pig uterus appears to be due to there being a pool of arachidonic acid bound as PC and/or PE which is readily releasable by PLA-2 and takes $3-5 \mathrm{~h}$ to refill completely. This time period taken to replete the pool may explain, in part, the pulsatile nature of uterine PGF- $2 \alpha$ synthesis. However, the continuous stimulation of PLA-2 by an intracellular second messenger, produced in response to the hormonal stimulus, would presumably not allow this pool of arachidonic acid to refill. Consequently, the pulsatile nature of PGF- $2 \alpha$ synthesis may also depend upon the intermittent stimulation of PLA-2 by a second messenger (e.g. calcium). The rate of incorporation of arachidonic acid into phospholipids of the guinea-pig endometrium is 2- to 3-fold higher on Day 15 than on Day 7 (Ning et al., 1983). Thus, the hormonal stimulus for uterine PGF-2 $\alpha$ production not only stimulates arachidonic acid release, but also increases the rate of arachidonic acid acylation into phospholipids.

This study was supported by a grant from the MRC. I thank Mrs L. Turnbull for technical assistance.

\section{References}

Barcikowski, B., Carlson, J.C., Wilson, L. \& McCracken, J.A. (1974) The effect of endogenous and exogenous estradiol $17 \beta$ on the release of prostaglandin $F_{2 a}$ from the ovine uterus. Endocrinology 95, 1340-1349.

Bennett, C.F. \& Crooke, S.T. (1987) Purification and characterisation of a phosphoinositide-specific phospholipase $\mathrm{C}$ from guinea-pig uterus. J. biol. Chem. 262, 13789-13797.

Downing, I. \& Poyser, N.L. (1983) Estimation of phospholipase $\mathrm{A}_{2}$ activity in guinea-pig endometrium on days 7 and 16 of the estrous cycle. Prostaglandins, Leuk. \& Med. 12, 107-117.

Flint, A.P.F., Leat, W.M., Sheldrick, E.L. \& Stewart, H.J. (1986) Stimulation of phosphoinositides by oxytocin and the mechanism by which oxytocin controls prostaglandin synthesis in the ovine endometrium. Biochem. J. 237, 297-805.

Fuse, I. \& Tai, H.H. (1987) Stimulation of arachidonate release and inositol-1,4,5-triphosphate formation are mediated by distinct G-proteins in human platelets. Biochem. Biophys. Res. Commun. 146, 659-665.

Leaver, H.A. \& Poyser, N.L. (1981) Distribution of arachidonic acid and other fatty acids in the lipids of guinea-pig uterus and plasma in relation to uterine prostaglandin synthesis. J. Reprod. Fert. 61, 265-271.

McCracken, J.A., Schramm, W. \& Okulicz, W.C. (1984) Hormone receptor control of pulsatile secretion of
PGF-2 $\alpha$ from the ovine uterus during luteolysis and its abrogation in early pregnancy. Anim. Reprod. Sci. 7, 31-55.

Mitchell, S., Poyser, N.L. \& Wilson, N.H. (1977) Effect of p-bromophenacyl bromide, an inhibitor of phospholipase $\mathbf{A}_{2}$, on arachidonic acid release and prostaglandin synthesis by the guinea-pig uterus. $\mathrm{Br} . J$. Pharmac. 59, 107-113.

Ning, A.C.W.S. \& Poyser, N.L. (1984) Further studies on the control of arachidonic acid turnover in guinea-pig endometrium in relation to prostaglandin production. Prostaglandins, Leuk. \& Med. 16, 285-302.

Ning, A.C.W.S., Leaver, H.A. \& Poyser, N.L. (1983) Arachidonic acid uptake into and release from guineapig endometrium in vitro on days 7 and 15 of the oestrous cycle. Prostaglandins, Leuk. \& Med. 10, 369-380.

Poyser, N.L. (1981) Prostaglandins in Reproduction. John Wiley \& Sons Ltd, Chichester.

Poyser, N.L. (1984) Effect of using calcium-free Krebs' solution on basal and A23187-stimulated prostaglandin output from the Day 15 guinea-pig uterus superfused in vitro. Prostaglandins, Leuk. \& Med. 13, 259-269.

Poyser, N.L. (1987) Effects of various factors on prostaglandin synthesis by the guinea-pig uterus. J. Reprod. Fert. 81, 269-276. 
Poyser, N.L. \& Brydon, L.J. (1983) Prostaglandin release from the guinea-pig uterus superfused in vitro. Effect of stage of estrous cycle, progesterone, estradiol, oxytocin and A23187. Prostaglandins 25, 443456.

Poyser, N.L. \& Scott, F.M. (1980) Prostaglandin and thromboxane production by the rat uterus and ovary during the oestrous cycle. J. Reprod. Fert. 60, 33-40.

Riley, S.C. \& Poyser, N.L. (1987) Effects of oestradiol, progesterone, hydrocortisone and oxytocin on prostaglandin output from the guinea-pig endometrium maintained in tissue culture. Prostaglandins 34, 535551.

Riley, S.C. \& Poyser, N.L. (1990) Is the inhibitory effect of progesterone on endometrial prostaglandin $F_{20}$ production due to an inhibition of protein synthesis? Prostaglandins, Leuk. \& EFA 39, 189-196.
Roberts, J.S., Barcikowski, B., Wilson, L., Skarnes, R.C \& McCracken, J.A. (1975) Hormonal and related factors affecting the release of prostaglandin $F_{2 a}$ from the uterus. J. Steroid Biochem. 6, 1091-1097.

Sheldrick, E.L. \& Flint, A.P.F. (1986) Transient uterine refractoriness after oxytocin administration in ewes. J. Reprod. Fert. 77, 523-529.

Swan, G.C. \& Poyser, N.L. (1983) Prostaglandin synthesis by, and the effects of prostaglandins and prostaglandin analogues on, the vas deferens of the rabbit and rat in vitro. J. Reprod. Fert. 69, 91-99.

Vallet, J.L. \& Bazer, F.W. (1989) Effect of ovine trophoblast protein-1, oestrogen and progesterone on oxytocin-induced phosphatidylinositol turnover in endometrium of sheep. J. Reprod. Fert. 87, 755-761.

Received 21 June 1990 